\title{
INFORMATION AND COMMUNICATIONS TECHNOLOGIES IN FUNCTION OF TEACHING PROCESS
}

\author{
NEBOJŠA DENIĆ ${ }^{1}$, SNEŽANA GAVRILOVIĆ ${ }^{2}$, NATAŠA KONTREC ${ }^{3}$ \\ ${ }^{1}$ Faculty of Sciences and Mathematics, University of Priština, Kosovska Mitrovica, Serbia \\ ${ }^{2}$ Technical College of Applied Studies in Mechanical Engineering, Trstenik, Serbia \\ ${ }^{3}$ Faculty of Sciences and Mathematics, Kosovska Mitrovica, University of Priština, Serbia
}

\begin{abstract}
This paper, based on the extensive research of relevant professional literature, will present and elaborate possible aspects of influence which information-communications technologies (ICT) have on educational process. Contemporary information-communications technologies and their use in teaching process resulted in numerous enhancements of teaching process altering traditional methods of learning and teaching. With the aim of confirming theoretical postulates researches were conducted on candidates with specific educational degrees in various forms of traditional teaching and teaching with educational software. The survey was conducted on a control and experimental group, on a sample of 1542 candidates. The candidates were observed in a period of approximately five months. The results of this research indicate that the candidates taught by use of educational software have shown far greater level of achieved knowledge and significantly higher motivation for learning. The participants of the experimental group actively participated in the acquisition of their competences. The contribution of this paper is in the new methodological approach to the organization of education, which significantly improves the teaching process, its goals and outcomes.
\end{abstract}

Keywords: Education, teaching, educational software.

\section{INTRODUCTION}

For many years the process of teaching was considered as the knowledge transfer process and the learning process as the process of receiving the aforementioned. The development of information and communications technologies and their use in teaching process resulted in fundamental role change in both teachers and students. This is exactly why the method of transfer and adopting knowledge changes continually. Rapid development of internet and contemporary sophisticated technologies is the main driving force and initiator of these changes. In relevant professional literature eminent authors use different determinants for concepts of use of educational software in education such as: distance learning, e-education, virtual education, e-learning, online learning (Moore et al., 2011). Based on their researches, the aforementioned authors concluded that almost all definitions of distance learning are similar in being a model of learning which includes two or more people, students and teachers, in different time intervals, locations and forms. Some authors, e.g. Nichols, (2003), define e-learning as a strictly technological tool based on web technologies, online transfer or online options. However, authors such as Benson, (2004), provided a clearer definition stating that online learning is a new and improved form of distance learning. Therefore, according to particular authors, the combination of traditional learning and distance learning deems most appropriate for majority of target groups (Bose, 2003). With regard the

\footnotetext{
* Corresponding author: nebojsa.denic@pr.ac.rs
}

INFORMATION TECHNOLOGIES utilization, authors (Georgouli et al., 2008) pointed out that the combined learning should be used to explain learning on several different ways and methods of learning as presented in figure 1.

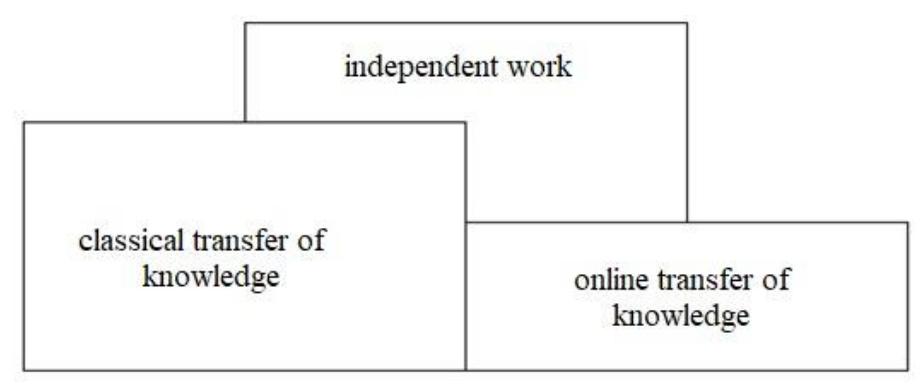

Figure 1. Combine learning.

Source: Georgouli et al., A Framework for Adopting LMS methods - to introduce e-Learning in traditional, 2008, str. 227.

The object and purpose of this research is to examine the applicability of educational software and how their application affects the motivation and active role of students in acquiring knowledge, as well as the quality of the acquired knowledge. The hypotheses of this research are:

- the application of educational software in the learning process motivates students to participate actively in acquiring their own competencies.

- knowledge gained through learning through educational software is more applicable and more extensive.

The thorough analysis of the application of educational software in the immediate teaching process, conducted during this research, is a guideline for the development of new 
methodological approaches and the improvement of teaching methodology.

\section{CONCEPT OF TEACHING WITH USE OF ICT}

In contemporary use of teaching process information and communications technologies represent, strictly speaking, unavoidable teaching asset as a support to teachers in traditional ways of learning and, broadly speaking, they represent a new methodological approach through various ways of realization of learning and teaching. "Multimedia teaching and learning according to eminent authors provide possibility for successful gaining of knowledge to all students in the class" (Chiou, 2008).

ICT implemented in teaching process as support to traditional ways of learning does not alter educational paradigm founded on transfer of knowledge from teacher to student, where teacher possesses knowledge and student is a passive receiver of knowledge. Such gained knowledge is, mostly, reduced to the model of reproduction of knowledge. The relationship between student, teacher and curriculum can be represented with the didactic triangle in figure 2. Element knowledge was omitted from this triangle because it is very difficult to determine quantity and quality of gained knowledge during the teaching process itself, when this type of teaching is conducted. Teaching is not adjusted to an individual but follows previously determined set of actions.

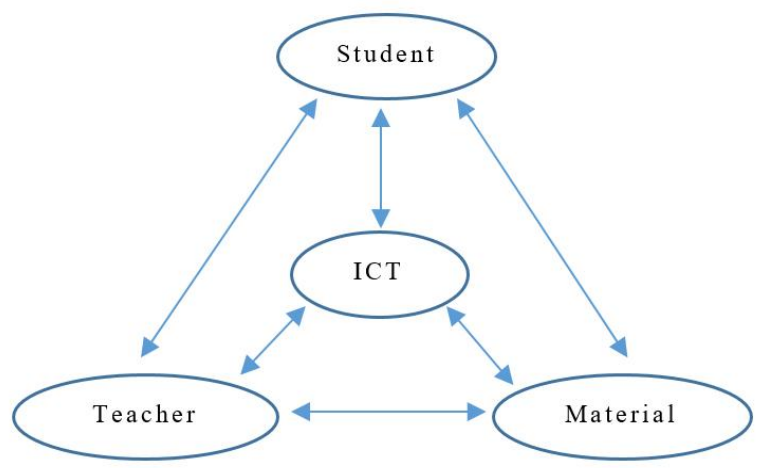

Figure 2. Didactic triangle.

New teaching methods of education with implementation of ICT imply an active student's role in his/her own education, and put the teacher in a position of professional adviser and coordinator of learning process. The model of reproduction of knowledge transforms into the model of understanding, upgrading and exploring new knowledge. The learning process is implemented with the utilization of various educational software and online platforms which require individual involvement of each student at his/her own pace. This type of gaining knowledge is possible with immediate mastering of teaching curriculum required for class continuation and adopting of new knowledge. The relationship between the student, teacher and curriculum is enhanced with the knowledge component and can be represented with didactic square in figure 3 .

This paper includes a comparison of these two methods of teaching with regard the aspects of motivation and adopted knowledge.

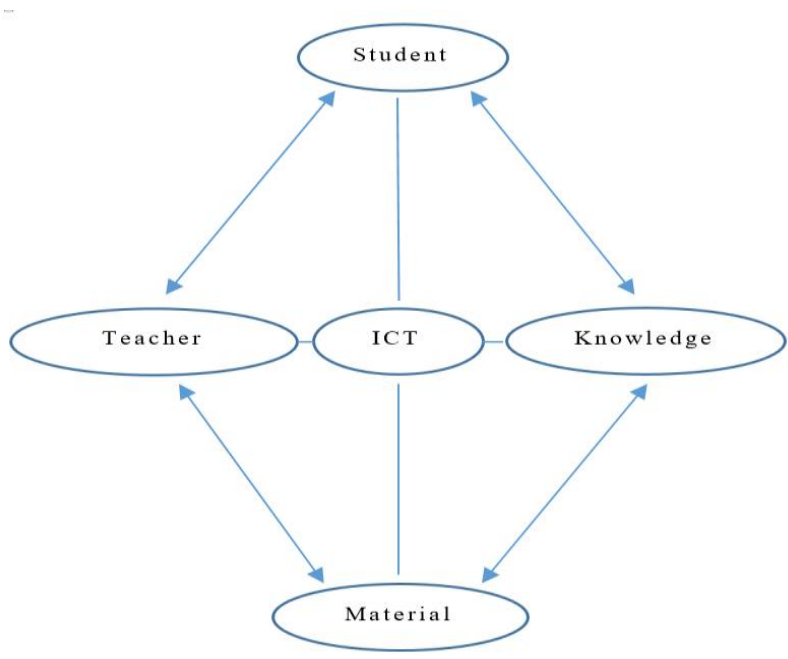

Figure 3. Didactic square.

\section{RESEARCH DESCRIPTION}

ECDL training for less employable groups was conducted within IPA 2020 project for Serbia. Candidates of younger age with III and IV degree of professional qualifications were selected within this program and, among other things, trained for work in Word and Excel. Training was conducted with the implementation of ECDL online educational software, and lecturer's presence. Trainees learned individually on ECDL online platform, with the use of educational software, while lecturer doubled as both mentor and coordinator of this process. This research included several municipalities of Raska district and an experimental group was founded in this way.

The second (control) group was consisted of the first year Higher Education Institutions' students from the same area, who learned to use Word and Excel during their first semester of Computer Science and Informatics class. The teaching process was traditional with the use of MS Office program packages (MS Word and MS Excel).

A computer lab was required for both groups in order for teaching to be adequate. The experimental group demanded free access to internet network, while the control group needed the required MS Office program package. Both groups had approximately the same number of classes during the implementation of these two modules.

The conducted research included method of analyses and synthesis and comparative method aiming at theoretical conclusions, also a poll and testing were used as a method for gathering data. Accumulated data were statistically processed in MS Excel program. 


\section{RESULTS AND DISCUSSION}

The implementation of ITC in teaching process has, undeniably, brought much news. The results of this research, among many others, pointed out several characteristics that make learning with the use of educational software different than traditional learning with ITC support.

Two groups were formed for the needs of this research:

- control group - consisted of 74 first year Higher Education Institutions' students

- experimental group - consisted of 68 ECDL trainees

Members of both groups have, prior to training, assessed their knowledge of MS Word text processing program and MS Excel table calculation program. According to figures 4 and 5, the level of previous knowledge, prior to training, was similar in both groups. Also, it was apparent that the group members assessed their knowledge of MS Word significantly better than MS Excel.

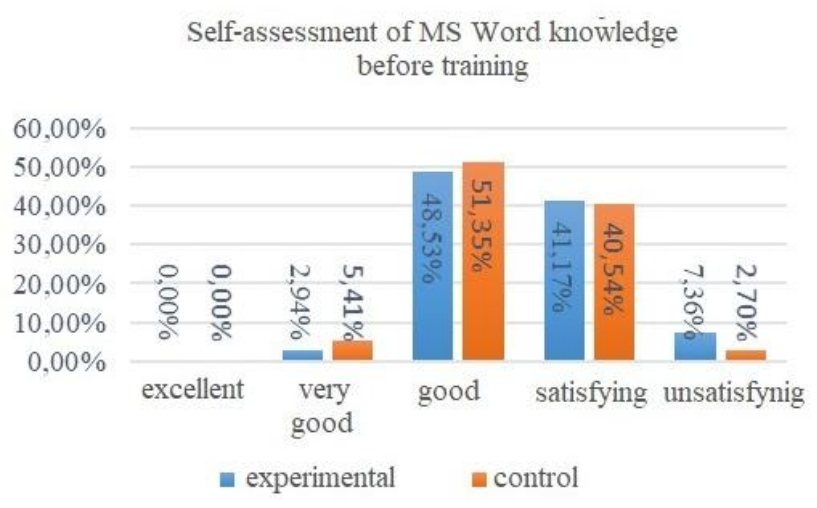

Figure 4. Self-assessment of MS Word knowledge before training.

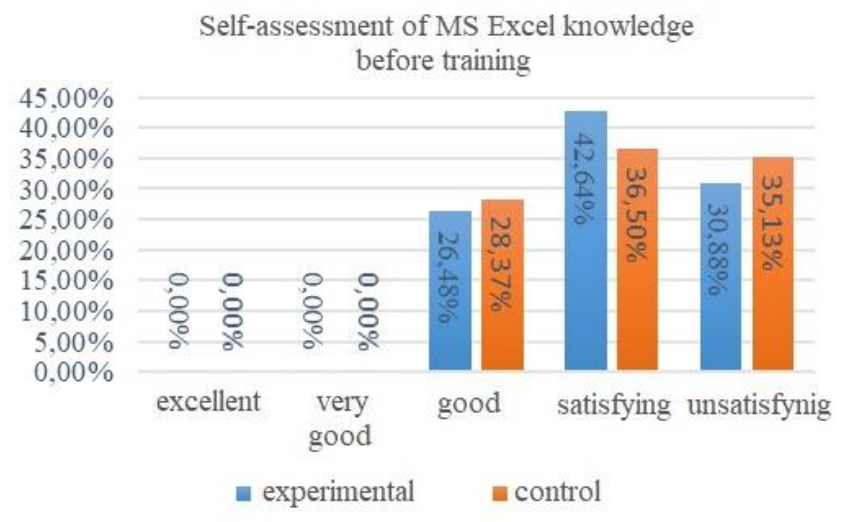

Figure 5. Self-assessment of MS Excel knowledge before training.

After training, the candidates re-assessed their knowledge. The results greatly differ, as shown on figures 6 and 7 .

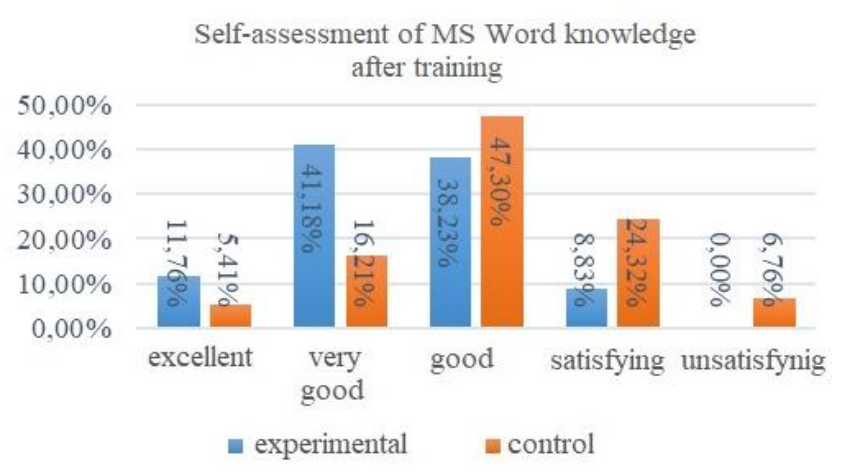

Figure 6. Self-assessment of MS Word knowledge after training

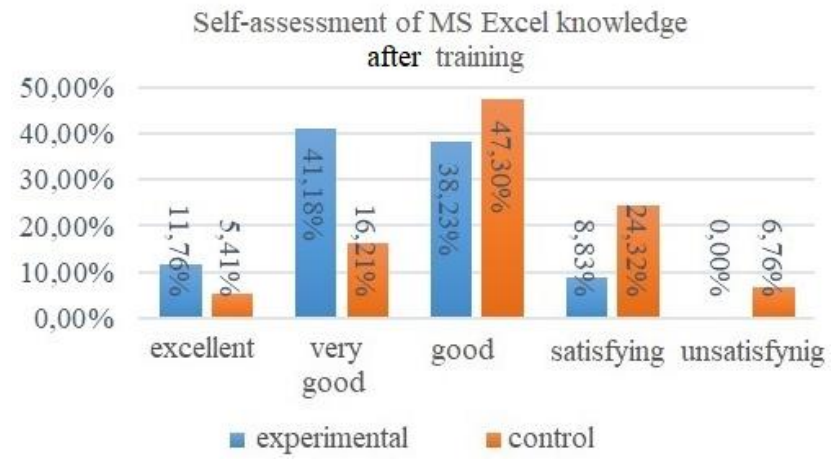

Figure 7. Self-assessment of MS Excel knowledge after training.

Based on the self-assessment of attendees from both groups, it is evident that members of the experimental group assessed their knowledge, upon completion of training, as significantly better than members of the control group.

In addition to having the group members self-assess their knowledge, the level of their knowledge was checked by expert teachers and lecturers. The results of this control are presented in table format, for each particular module - Table 1 and Table 2, and summed up for entire training program - Table 3. Members of the control group were assessed on 1-100 scale; with basic level is from 51-65, medium level from 66-85 and higher level from 86-100. Assessment scale for members of the experimental group was from 1-36 points. Basic level was attained with 27-29 points, medium from 30-36 and higher from 34-36 points.

Table 1. Expert's assessment for results in Word.

\begin{tabular}{|c|c|c|c|c|}
\hline MS Word & 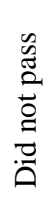 & 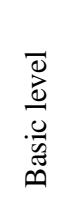 & 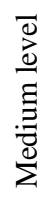 & 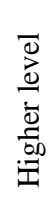 \\
\hline $\begin{array}{l}\text { Control } \\
\text { group }\end{array}$ & 8 & 38 & 21 & 7 \\
\hline $\begin{array}{c}\text { Experimental } \\
\text { group }\end{array}$ & 0 & 8 & 41 & 19 \\
\hline
\end{tabular}


Results concerning answers to several important questions are shown in figures 8,9 and 10 . Those results stress a major difference between teaching in control and experimental group, i.e. key differences between traditional teaching and teaching with the use of educational software can be seen.

Table 2. Expert's assessment for results in Excel.

\begin{tabular}{|c|c|c|c|c|}
\hline MS Excel & 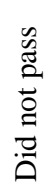 & 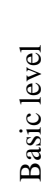 & 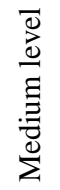 & $\begin{array}{l}\bar{d} \\
\bar{d} \\
\overline{\bar{d}} \\
\overline{0} \\
\overrightarrow{00}\end{array}$ \\
\hline $\begin{array}{l}\text { Control } \\
\text { group }\end{array}$ & 11 & 34 & 24 & 5 \\
\hline $\begin{array}{l}\text { Experimental } \\
\text { group }\end{array}$ & 2 & 13 & 37 & 16 \\
\hline
\end{tabular}

Table 3. Expert's assessment for results - in total.

\begin{tabular}{|c|c|c|c|c|}
\hline Total & 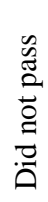 & 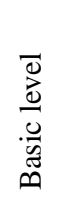 & $\begin{array}{l}\bar{\Xi} \\
\stackrel{\Xi}{\Xi} \\
\Xi \\
\stackrel{\Xi}{\Xi}\end{array}$ & 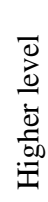 \\
\hline $\begin{array}{l}\text { Control } \\
\text { group }\end{array}$ & 12 & 33 & 24 & 5 \\
\hline $\begin{array}{c}\text { Experimental } \\
\text { group }\end{array}$ & 2 & 11 & 39 & 16 \\
\hline
\end{tabular}

It can also be seen that members of the experimental group, learning with the use of educational software, were significantly more motivated for work than members of the control group learning traditionally with the use of ICT.

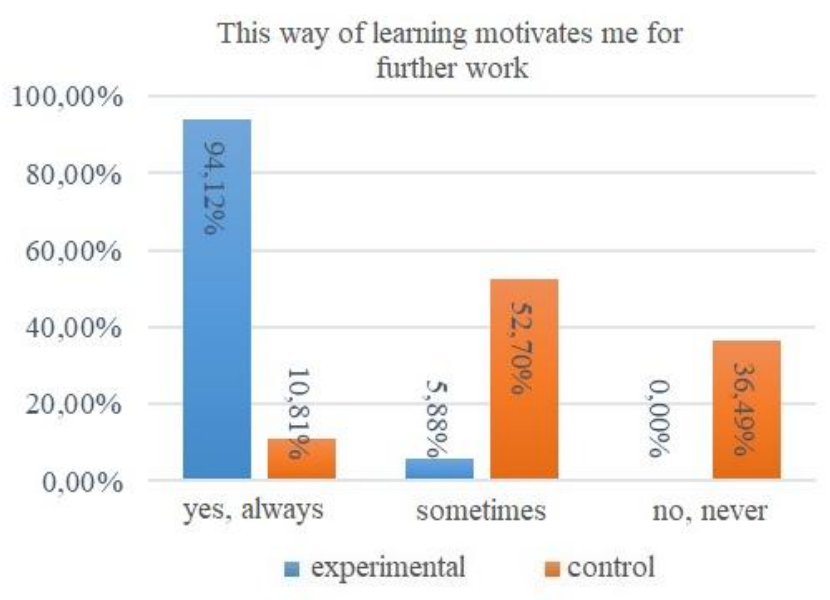

Figure 8. Motivation.

It becomes apparent that the teaching organized with the use of educational software demands major active participation of each individual and enables attendees to learn at their own pace and in accord with their own abilities. Muller et al., (2006) also confirmed these postulates pointing out that implementation of ITC, i.e. educational software, in teaching, provides opportunity for each pupil-student to process content and make progress in accordance with his/her own individual affinities and abilities (Muller et al., 2006). The fact, confirmed with this research, that the quality of knowledge adopted with the help of educational software is much better could be added to the existing eminent literature. Namely, the educational software arouses the research spirit and requires of students to use previously acquired knowledge while acquiring new one at all times.

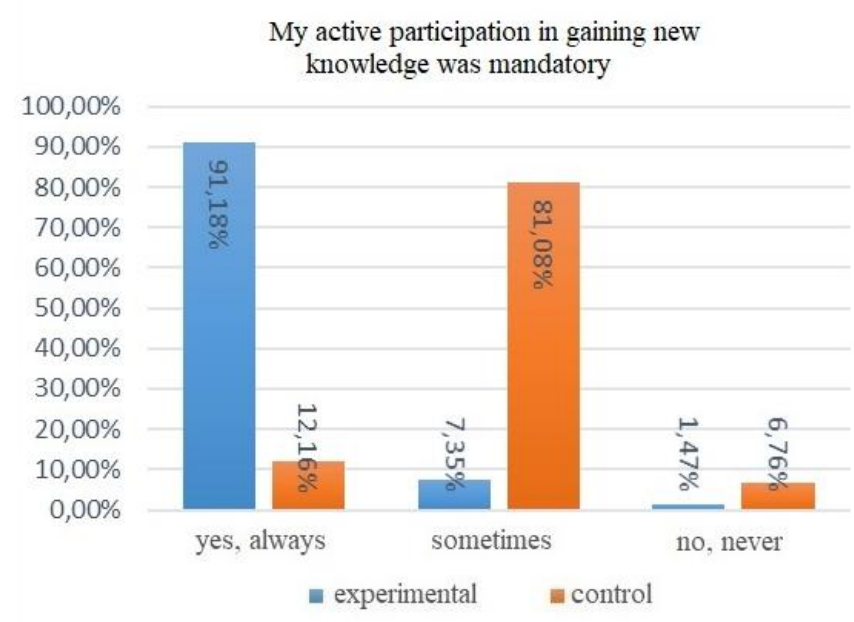

Figure 9. Active teaching.

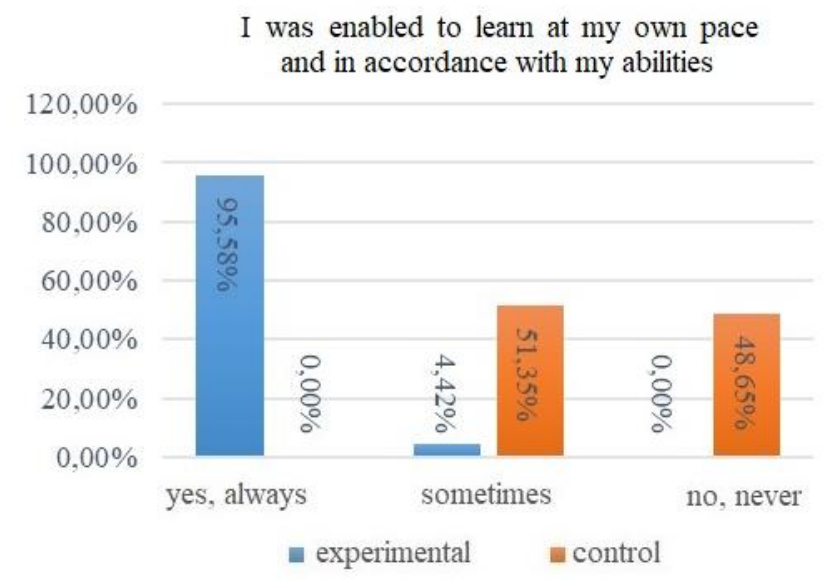

Figure 10. Individual teaching.

Members of both groups stated that they were able to gain new knowledge regardless of their foreknowledge, and that interlinking of obtained knowledge was mandatory in order to receive additional knowledge. Members of control group stated that teacher's assistance was mandatory for gaining new knowledge, while members of experimental group stressed they were able to obtain new knowledge without teacher's key assistance, with the use of educational software.

Concerning the quality of gained knowledge, the difference between groups is evident. With regard MS Word, the experimental group achieved better results, with 60 members 
reaching medium and higher level; whilst 59 attendees of control group reached basic and medium level. With regard MS Excel, the results are almost the same: 58 attendees in control group reached basic and medium level and 63 attendees of experimental group reached medium and higher level. Finally, summarizing both modules results in the following: the level of gained knowledge in control group is focused on basic level with $44,59 \%$, while medium level was reached by $32,43 \%$. The highest level was reached by $6,76 \%$ only. Medium and higher level was reached by $80,88 \%$ in experimental group, wherein $57,35 \%$ reached medium and $23,53 \%$ reached higher level.

The aforementioned results were confirmed with theoretical reasearches conducted by numerous reputable international authors (Chaney-Cullen \& Duffy, 1999; Muller et al., 2006; Forgasz, 2006; Hwanga et al, 2007), pointing out immense, indisputable advantages of utilization of ICT and educational software in teaching and also regarding quality of gained and adopted knowldege, motivation of students for work and improvement of overall teaching process in general. As reasons for insufficient and inadequate implementation of ICT i.e. computers and educational software in teaching; particularly in chemistry, biology and physics classes; teachers stressed inadequate and insufficient providing of related IT equipment to educational institutions - computers, software, access to internet and stabile internet connection and the lack of suitable multimedia materials etc.

\section{CONCLUSION}

Results of research presented in this paper point out what should be the goal for contemporary teaching - enabling pupils and students to obtain new information which they will be able to understand and critically analyze by themselves, from different sources of knowledge. Implementing new technologies, ICT and educational software in particular, is highly important for contemporary teaching. With the utilization of ICT everyone can share their data and information with other users that use Information and communications technologies (ICT), i.e. as much as one is IT literate or enabled. In general, it can be said that information literacy represents a set of knowledge and skills that users need to obtain and which can be improved and enhanced from available sources, creating new knowledge, skills and abilities. The results of this research point out, beyond doubt, that implementation of ICT in learning process and teaching requires well and clearly defined goals, and that learning should be less about memorizing facts and data and more about acquiring skills and practically applicable scientific knowledge. Based on theoretical studies and conducted researches in educational institutions in the Republic of Serbia it can be concluded that in order to have a successful implementation of ICT in teaching process, the following activities are mandatory: improving of conditions for work and learning in educational institutions of the Republic of Serbia, which significantly increases the quality of teaching and learning process; acquiring those skills and knowledge related to contemporary conceptual technological processes. In addition to the aforementioned, professional and methodical education of teaching personnel involved in education of students in the areas of basic ICT knowledge, effects and consequences its implementation has on an individual and society in general, is also required. In accordance with the IT Development Strategy in the Republic of Serbia, it is required to have extensive organization of training which would provide educational workers with appropriate instructions, guidelines and knowledge on fulfillment of conditions and ways to implement ICT integration and educational software in teaching process; furthermore, to stimulate lecturers and educational workers to improve their knowledge and skills, favoring team work and cooperation both within teachers and educators as well as in pupils, i.e. students. In order to overcome difficulties and deficiencies in educational work, transforming educational institutions into research facilities is necessary, wherein pupils/students will not only copy data and information but become active researchers and well trained and sufficiently educated for resolving specific situations and problems. That being said, it is certainly vital to enable exchange of knowledge between educational workers and educators on related use of ICT and educational software in teaching as well as coordinating the needs of national institutions and facilities for teaching personnel which will become fully literate in this manner. Results of researches conducted in neighboring countries undoubtedly indicate that labor market has utmost need for experts armed with knowledge and skills, guaranteeing success in society and that education is a continual process and a category that should last throughout the life cycle through the life-long process of learning implemented more and more in the world.

\section{REFERENCES}

Benson, P.E. 2004. Online learning: A means to enhance professional development. Crit Care Nurse, 24(1), pp. 60-3. pmid:15007894

Bose, K. 2003. An e-learning experience-a written analysis based on my experience in an e-learning pilot project. CampusWide Information Systems, 20(5), pp. 193-199.

Chaney-Cullen, T., \& Duffy, M.T. 1999. Strategic Teaching Framework: Multimedia to Support Teacher Change. The Journal of the Learning Sciences, 1, pp. 1-40. Taylor \& Francis. doi:http://www.jstor.org/stable/1466703

Chiou, C. 2008. The effect of concept mapping on students learning achievements and interests. Innovations in Education \& Teaching International, 45(4), pp. 375-387.

Forgasz, H. 2006. Factors That Encourage Or Inhibit Computer Use For Secondary Mathematics Teaching. Journal of Computer Use For Secondary Mathematics Teaching, 25(1).

Georgouli, K., Skalkidis, I., \& Guerreiro, P. 2008. A Framework for Adopting LMS to Introducee-Learning in a 
Traditional. Educational Technology \& Society, 11(2), pp. 227-240.

Hwanga, W.Y., Wang, C.Y., \& Sharples, M. 2007. A study of multimedia annotation of Webbased materials. Computers \& Education, 48, pp. 680-699. Retrieved from www.sciencedirekt.com
Moore, J., Dickson-Deane, C., \& Galyen, K. 2011. E-Learning, online learning, and distance learning environments: Are they the same? Internet and Higher Education, 14, pp. 129-135.

Muller, D., Eklund, J., \& Shanna, M. 2006. The future of multimedia learning. In Essential Issues for Research. Australia: University of Sydney NSW.

Nichols, M. 2003. A theory for eLearning. Journal of Educational Technology \& Society, 6(2), p. 76. 